\title{
Original Research \\ Behavioural aspects surrounding medicine purchases from pharmacies in Australia
}

Lynne EMMERTON.
Received (first version): 2-May-2008

Accepted: 28-Jul-2008

\begin{abstract}
${ }^{\star}$
Objective: This study aimed to produce current data regarding behavioural aspects of non-prescription (over-the-counter) medicine purchases, in light of changes in the pharmaceutical market and increasing provision of professional services in pharmacies.

Methods: Data were collected in 15 community pharmacies in South-East Queensland, Australia, over 540 hours in five days in August, 2006. The method, previously validated, involved documentation of both observational and interview data. Fifteen trained researchers were stationed in a selected pharmacy each to unobtrusively observe all eligible sales of non-prescription medicines, and, where possible, interview the purchasers post-sale. Non-response was supplemented by observational data and recall by the salesperson. The data included details of the purchase and purchasing behaviour, while new questions addressed issues of topical importance, including customers' privacy concerns. A selection of the analyses is reported here.

Results: In total, 3470 purchases were documented (135-479 per pharmacy), with customers of $67.5 \%$ of purchases (74.7\% excluding an outlier pharmacy) participating in the survey. Customers averaged 1.2 non-prescription medicines per transaction. Twothirds $(67.2 \%)$ of customers were female, and $38.8 \%$ of the customers were aged $31-45$ years. Analgesics and respiratory medicines accounted for two-thirds of the sales data $(33.4 \%$ and $32.4 \%$, respectively). Intended-brand purchases comprised $71 \%$ of purchases $(2004 / 2824)$; in-store substitution then occurred in $8.8 \%$ of these cases, mainly following recommendations by pharmacy staff. Medicines intended for self-use comprised $62.9 \%$ of purchases (1752/2785). First-time purchases $(30.8 \%, 799 / 2594)$ were more commonly influenced by pharmacy staff than by advertising.

Conclusions: This study used validated methods adapted to a changing marketplace, thus providing data that both confirm and add to knowledge surrounding medicine purchases. Despite the dynamics of the non-prescription market, it revealed consistencies with previous research.
\end{abstract}

Keywords: Drugs, Non-Prescription. Self Medication. Australia.

\footnotetext{
Lynne EMMERTON. BPharm(Hons), PhD, MPS. Senior Lecturer. School of Pharmacy. The University of Queensland. Queensland (Australia).
}

\author{
ASPECTOS COMPORTAMENTALES EN \\ TORNO A LA COMPRA DE \\ MEDICAMENTOS EN FARMACIAS EN \\ AUSTRALIA
}

\section{RESUMEN}

Objetivo: Este estudio trató de producir datos actuales en relación a los aspectos comportamentales de la compra de medicamentos sin receta (OTC), a la luz de los cambios en el mercado farmacéutico y el aumento de la prestación de servicios en las farmacias. Métodos: Se recogieron datos de 15 farmacias comunitarias del sur-este de Queensland, Australia, durante 540 horas en 5 días en agosto de 2006. El método, previamente validado, implicaba la documentación de datos tanto observacional como de entrevista. Quince investigadores entrenados se situaron en cada una de las farmacias seleccionadas para observar sin intervenir en todas las ventas elegibles de medicamentos sin receta y, cuando era posible, entrevistar al comprador después de la venta. La no respuesta se complementaba con datos observacionales y recuerdos del vendedor. Los datos incluían detalles de la compra y la actitud de compra, mientras que potras preguntas afrontaban asuntos de importancia, incluso preocupaciones privadas del cliente. Aquí se comunica una selección de los análisis.

Resultados: En total se documentaron 3470 compras (135-479 por farmacia), con el 67,5\% de los clientes participantes en el estudio $(74,7 \%$ excluyendo una farmacia outlier). Los clientes compraron 1,2 medicamentos de media por compra. Dos tercios $(67,2 \%)$ de los clientes eran mujeres, y el 38,8\% tenían entre 31-45 años. Analgésicos y medicamentos respiratorios totalizaron dos tercios de las ventas (33,4\% y 32,4\% respectivamente). Las compras con marca deseada llegaron al $71 \%$ del total (2004/2824); la sustitución de la marca ocurrió en el 8,8\% de estos casos, principalmente después de recomendaciones del personal de la farmacia. Los medicamentos para si mismo sumaron el $62,9 \%$ de las compras $(1752 / 2785)$. Los compradores por primera vez $(30,8 \%, 799 / 2594)$ eran más fácilmente influenciables por el personal de la farmacia que por la publicidad.

Conclusiones: Este estudio usó métodos validados adaptados a un mercado cambiante, proporcionando así datos que confirman y añaden conocimiento sobre la compra de medicamentos. A pesar de la dinámica del mercado sin receta, se revelaron consistencias con estudios previos.

Palabras clave: Medicamentos sin receta. Automedicación. Australia. 


\section{INTRODUCTION}

Community pharmacies in Australia are an accessible and trusted source of non-prescription medicines ${ }^{1}$, and approximately one in 25 members of the public receive advice in a pharmacy per fortnight. ${ }^{2,3}$ Medicines available without prescription from pharmacies in Australia are legally classified as either unscheduled (also sold in non-pharmacy outlets), Pharmacy Medicines (available in pharmacies, sold under supervision of a pharmacist), or Pharmacist Only Medicines (requiring a pharmacist's advice on selection and use). ${ }^{4}$ The availability of these medicines and involvement of pharmacy staff in their provision saves significant secondary health care costs. Equivalent non-prescription schedules exist in New Zealand and Canada, while non-prescription medicines in the United Kingdom and France are classified as either 'general sale' or 'pharmacy only'. In the United States, medicines are either 'general sale' or available on prescription; an intermediate classification has been mooted since the 1980 s. $^{5}$

The non-prescription medicine market includes products such as cough and cold, dietary supplements and analgesics categories. The availability of generic medicines as alternatives for off-patent proprietary medicines is expected to maintain strong growth. ${ }^{6}$

Another significant trend is the rescheduling or 'descheduling' of medicines, commonly from prescription-only availability to the Pharmacist Only Medicine schedule, with increased responsibility for pharmacists to monitor and advise on sales ${ }^{3}$, or from Pharmacy Medicine to open-sales status, which can increase sales if then supplied by nonpharmacy retailers, and places greater responsibility for pharmacovigilance on the consumer.

The size and importance of the non-prescription medicine market suggests that dynamic market forces exist and are likely to impact on consumer and pharmacy staff behaviour. The impact of pharmaceutical marketing on consumers and health care professionals, particularly for newlyrescheduled and newly-launched products, is unclear. The only formal sales tracking system in place in Australia is for pseudoephedrine-containing medicines, involving online validation of the purchaser's identity; ${ }^{8,9}$ no data are available to report on the practical impact of this system or the rescheduling of most pseudoephedrine-containing medicines, which took place in early 2006 . $^{10}$

These developments together suggest a need to maintain current data on the nature and behavioural descriptors of non-prescription medicine purchases, to guide professional initiatives and marketing in the provision of over-the-counter services in pharmacies. Numerous international studies have attempted to address aspects of this topic in the past decade, using questionnaires distributed for self-completion by pharmacy customers ${ }^{11}$, large- scale market research ${ }^{12,13}$ and in-store interviews by researchers. ${ }^{14-20}$ Interview methods, despite being labour intensive, have achieved the highest response rates and facilitate data validity.

Demographic research has identified that females comprise around two-thirds of non-prescription medicine purchasers ${ }^{15,18-22}$ and the majority of pharmacy customers overall. ${ }^{3}$ National market research, using a representative sample of the population aged 15-65 years, has described pharmacy customers as commonly families and "empty nesters" ${ }^{23}$ and non-prescription medicine customer surveys have determined a dominance of purchasers aged 30 to 50 years. ${ }^{18,20-22}$ Some behavioural research findings relating to the involvement of pharmacy assistants in medicine sales, the dominance of intended-brand purchases and purchases for self-use have been consistent between three previous mid-winter surveys of nonprescription medicine purchasers in samples of six to 15 pharmacies in Australia and New Zealand. ${ }^{18,20,21}$

While studies have established general characteristics of non-prescription medicine purchases and customers, market dynamics and influences of regulatory and professional pharmacy bodies indicate a need to maintain current data, monitor trends and explore topical issues of importance to the pharmacy profession.

Therefore, this study aimed to:

1. Validate previously reported characteristics of non-prescription medicine purchases, including the categories of medicines purchased, demographic descriptors of the customers and key purchasing behaviour variables.

2. Establish baseline data on a number of novel issues and analyses (including legal schedule of the medicine, privacy concerns, perception of whether verbal and/or written advice had been provided, location of the medicine in the pharmacy, multiple purchases, and gender effects) that further describe the non-prescription medicine market. For economy, this paper reports on a selection of the analyses.

This was exploratory research based on assumptions that medicine purchasers are capable of verbalising their behavioural intentions and recognising influences on their medicine choice, and that customer-generated and observational data are accurate descriptors of purchasing behaviour.

\section{METHODS}

This study was a fourth application of a method previously developed in New Zealand in 1999, involving 12 pharmacies, ${ }^{18,19}$ South-East Queensland in 2004 , involving 15 pharmacies, ${ }^{17,20}$ and New Zealand in 2005, involving six pharmacies. ${ }^{21}$ The pharmacy managers provided written consent for their pharmacy to be used for data collection. The study was approved by the Human Research Ethics Committee of the research institution (approval 2006000349). 
Non-prescription medicine customers were interviewed following their purchase(s), by final-year pharmacy students. The questionnaire, a revised version of that applied in the previous studies, and retaining the bi-fold pamphlet format previously found acceptable ${ }^{17}$, identified the product purchased, its intended use, the intended user, influences on first-time purchases, intention to purchase a particular brand, mode of purchase, instore substitutions, characteristics of the purchaser, and observed product-related consultation with a staff member. The questionnaire from previous applications of this method was modified to streamline the ranking of influences and address topical issues: legal schedule of the medicine, privacy concerns, perception of whether verbal and/or written advice had been provided, and location of the medicine in the pharmacy; these had not been validated by previous research and thus provided novel data.

In the same manner as the previous applications of this method ${ }^{15,21,24}$, each researcher was stationed in a selected pharmacy for five business days during a defined week (5-13 August 2006), determined by the students' allocated project period. Previous applications have indicated that a sample size of 2400 medicine sales would permit testing of hypotheses regarding key purchasing behaviour and demographic variables with significance of $p<0.05$ and power $\geq 0.8$, and that an average of 200 records per five-day period (35 hours) was achievable. Thus, a cohort of 15 pharmacies (15 researchers) was determined to exceed the minimum sample size requirements.

The pharmacies were selected to represent a range of sizes (range of 1-3 pharmacists, mean 1.5, and 1-15 pharmacy assistants, mean 4.7), inner-city $(n=2)$ and suburban $(n=6)$ sites through Brisbane and regional sites $(n=6)$ within a $200 \mathrm{~km}$ radius of Brisbane, and a range of pharmacy types: discount (warehouse-style) pharmacies $(n=4)$, other 'banner groups' (equivalent to 'chain' pharmacies) $(n=4)$ and independently-owned pharmacies $(n=6)$, including one medical centre pharmacy and one adjacent to a medical specialist. Discount pharmacies were considered important to include for research into price-based purchasing behaviour. Banner group pharmacies market a range of self-labelled generic medicines of interest to this study.

The research group received training for consistency in recruitment and data management, and electronic communication was maintained throughout the project. Researchers were positioned to unobtrusively record observational data for all witnessed sales of eligible nonprescription medicines. In accordance with the ethical approval for this study, the researchers were able to note whether an eligible sale had occurred, but not in a position to overhear or intrude on the conversation. Non-prescription medicines were defined as Pharmacy Medicines, Pharmacist Only Medicines and unscheduled medicines that contain an active ingredient for a specific purpose, including nutritional supplements and excluding food items, non-medicated dressings and sunscreens.
Purchasers of the medicines were to be at least 16 years of age and conversant in English for inclusion.

All eligible purchasers of the medicines were interviewed with their verbal consent. In the case of non-participation, the partial data recorded by observation, then validated or supplemented by recall of the pharmacy staff member, were included for analysis.

Data entry involved customised coding of the medicines, accessed online and allowing real-time addition to the list. Screening of the 15 merged datasets included checks by the author for invalid codes, responses and response patterns, and a pair of researchers was commissioned for seven hours of random checking. The final error rate was estimated at one datum per 10 questionnaires. Analysis was undertaken using SPSS version 13.0 for descriptive statistics and tests for differences between dependent groups (chi-square, one-way ANOVA), with significance determined at $p<0.05$.

\section{RESULTS}

\section{Description of the sample}

Over the 540 hours of data collection, 3470 nonprescription purchases (by 2813 customers) were documented in the 15 participating pharmacies, ranging from 135 to 479 purchases per pharmacy. Two-thirds $(67.5 \%)$ of the purchases $(n=2334)$ were represented by customers' participation in the survey, ranging from $22.8 \%$ in a large discount pharmacy to $100.0 \%$ in a suburban pharmacy with loyal clientele. The participation rate was $74.7 \%$ excluding the large discount pharmacy. Time pressure comprised $74.5 \%$ of reasons for nonparticipation. Projections over researchers' breaks indicated that this survey captured at least partial data for $89.8 \%$ of all eligible sales during the data collection hours.

Two-thirds (67.2\%) of customers were female (1885/2805), ranging $49.7 \%$ to $76.2 \%$ per pharmacy, with no clear relationship with pharmacy location or other characteristics. The majority of customers $(38.8 \%, 713 / 1839)$ were aged $31-45$ years. The proportion of females dominated males in the 31-50-year brackets. Most commonly, customers declared that they had two regular pharmacies $(45.0 \%, 834 / 1852)$.

Analgesics, including medicines for pain, inflammation, fever and musculoskeletal symptoms, accounted for $33.4 \%$ of the sales (1159/3469), followed closely by respiratory medicines (for coughs and colds and sinus, hay fever, allergic and asthma symptoms) at $32.4 \%$ (1125/3469). Excluding data from the aforementioned discount pharmacy, the analgesics and respiratory medicine groups comprised $30.1 \%$ and $33.1 \%$ of sales, respectively. Nutritional supplements comprised $10.5 \%$ of sales (363/3469), while the remaining categories were relatively minor.

\section{Purchasing behaviour}

Customers averaged 1.2 different non-prescription medicines per transaction, excluding any 
prescription and non-medicated items also purchased. The large discount pharmacies were associated with purchases of more than one different medicine and of multiple packs of the same medicine in the one transaction. One discount pharmacy averaged 1.7 different medicines per transaction, and in another, up to six packs of a brand of paracetamol were purchased together. Purchases of more than one different medicine were more likely to be associated with self-selection by customers than single-medicine purchases (chisquare $=38.9, \mathrm{df}=2, \mathrm{p}<0.001$ ), and female customers rather than males (chi-square $=30.2, d f=2, p<0.001$ ).

The average expenditure per medicine was AUD 11.63 (USD 8.89), ranging from an average of AUD 7.38 (USD 5.64) in the analgesics category to AUD 27.08 (USD 20.71) for 'miscellaneous' medicines, which included weight loss, hair loss and smoking cessation products.

Overall, $62.9 \%$ of the purchases $(1752 / 2785)$ were intended for self-use, with $30.0 \%(835 / 2785)$ for another person and $7.1 \%(198 / 2785)$ for sharing. Female customers were more likely than males to have bought a medicine for another person or for sharing (chi-square=42.6, df=2, $p<0.001$ ). 'Other people' were most commonly children under 16 years $(57.5 \%, 423 / 736)$.

Repeat purchases comprised $69.2 \%$ of sales (1795/2594). First-time purchases exceeded repeat purchases in only one of the 15 pharmacies, located in a medical centre (115 vs 95 sales, respectively). Purchases made with a particular brand in mind and intended for sharing were more likely to have been repeat purchases than those for self-use or for another person (chi-square $=15.5, \mathrm{df}=2, \mathrm{p}<0.001$ ).

The influences on first-time purchases were analysed. A single 'most important' influence was indicated in 806 of 975 responses, most commonly 'pharmacy staff' $(56.9 \%, 459 / 806)$, followed by 'doctor' (19.9\%), 'family/friends' (11.3\%) and advertising sources (in-store and via external media, $6.2 \%$ combined). Fifty-five 'other' influences mostly related to price $(n=19)$ or experience with a similar product $(n=10)$. 'Pharmacy staff' was the primary influence for both intended-brand and nointended-brand purchases, although doctors were also a major influence in the former (Table 1 ).

\begin{tabular}{|l|r|r|r|r|r|r|}
\hline Table 1: Influences on First-Time Purchases \\
\hline Influence & \multicolumn{2}{|c|}{ No brand in mind } & \multicolumn{2}{|c|}{ Brand in mind } & \multicolumn{2}{|c|}{ Total } \\
\hline Pharmacy staff & 428 & $77.3 \%$ & 126 & $22.7 \%$ & 554 & $100.0 \%$ \\
\hline Doctor & 50 & $29.8 \%$ & 118 & $70.2 \%$ & 168 & $100.0 \%$ \\
\hline Family/friends & 46 & $43.4 \%$ & 60 & $56.6 \%$ & 106 & $100.0 \%$ \\
\hline In-store advertising & 35 & $81.4 \%$ & 8 & $18.6 \%$ & 43 & $100.0 \%$ \\
\hline Other advertising & 18 & $43.9 \%$ & 23 & $56.1 \%$ & 41 & $100.0 \%$ \\
\hline Other influence & 34 & $57.6 \%$ & 25 & $42.4 \%$ & 59 & $100.0 \%$ \\
\hline Total & 611 & $62.9 \%$ & 360 & $37.1 \%$ & 971 & $100.0 \%$ \\
\hline chi square=184.0, df=5, $\mathrm{p}<0.001 . \mathrm{n}=4$ missing data for 'brand in mind' variables \\
\hline
\end{tabular}

In $29.0 \%$ of all purchases (820/2824), the customer had decided on a brand in-store. In the majority of these cases, the customer relied on a professional recommendation by pharmacy staff, or requested a product by drug group or generic drug name. Unguided self-selection of medicines occurred in $12.6 \%$ of no-intended-brand purchases $(103 / 817)$ (Figure 1). For broader comparison, $20.1 \%$ of all medicines purchased $(687 / 3416)$ were obtained from areas designated for self selection (front-shop shelves or 'specials bins', as opposed to behindthe-counter or the dispensary). There was a tendency for female customers to either self-select medicines or describe symptoms to seek a recommendation by a staff member, while male customers tended to request a product by drug name or drug group (chi-square $=15.1, d f=3$, $\mathrm{p}<0.02$ )

Eighty-nine percent of the intended-brand purchases were undertaken by asking a staff member for that brand, regardless of the product's accessibility for self-selection. Of the intendedbrand purchases, $8.8 \%$ (174/1988) were substituted in-store, most commonly as a result of intervention by pharmacy assistants or pharmacists $(42.8 \%$ of 238 reasons cited). Selection of a cheaper alternative accounted for $31.1 \%$ of the reasons.
There were 19 cases of privacy concerns by the purchases $(0.8 \%$ of 2353 responses), with explanation provided for 18 of these. Eight related to collection of personal details, legally required for Pharmacist Only Medicine sales. Seven concerned consultations being overheard, and three related to embarrassing health conditions. Further analysis of this issue, including staff members and products involved, will be reported in a future publication.

\section{DISCUSSION}

\section{Methodological issues}

This study method generated a substantial empirical database providing an insight into the social dynamics of the non-prescription medicine market, in a changing environment influenced by pharmaceutical industry, regulatory bodies and pharmacy organisations. While three previous applications have developed and validated the method, this study is the largest and most recent. It introduced a number of new analyses and insight into topical issues such as multiple purchases, privacy concerns and accessibility of the medicine. The breadth and size of the database allows exploration of particular phenomena, including analysis by product group, and the potential for multivariate modelling is acknowledged, for example, to examine purchases of drugs of abuse in terms of behavioural and demographic predictors. 


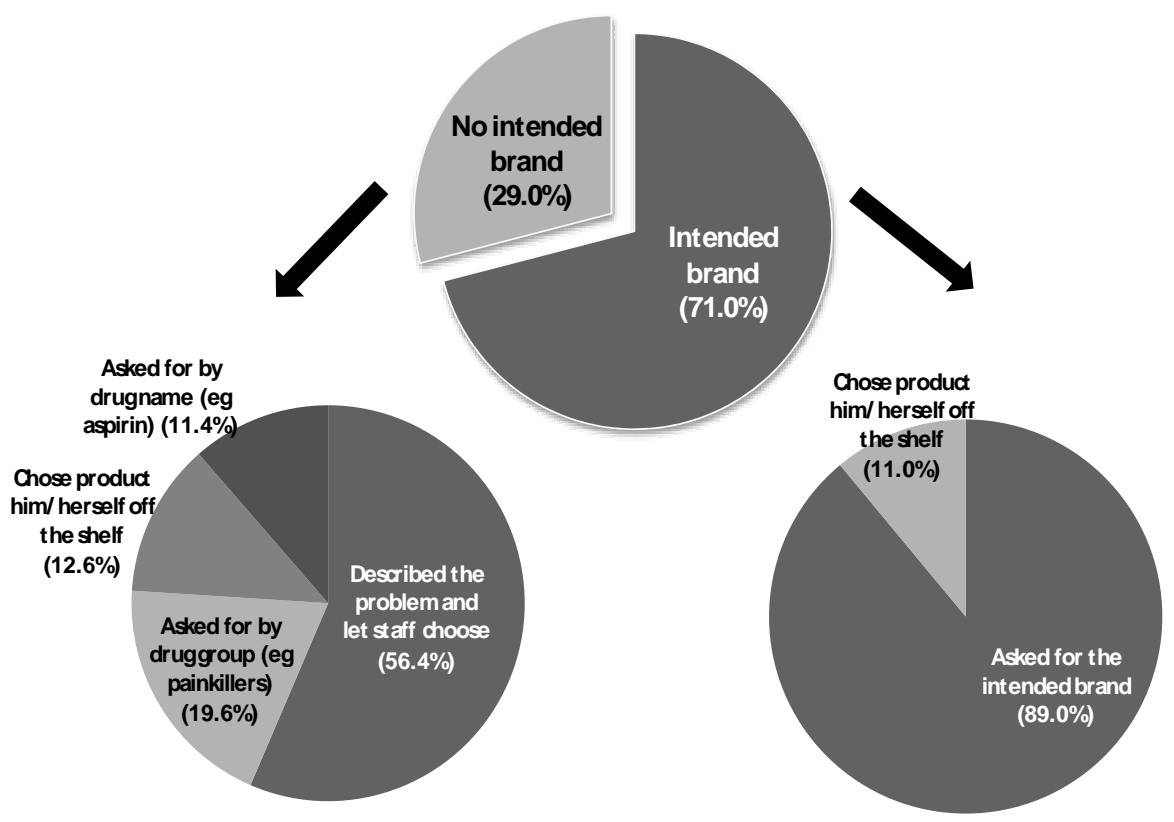

Figure 1: Mode of Purchase ( $n=2824$ medicines $)$

Repeated use of this method has demonstrated reproducibility and acceptability in terms of data quality. The customer participation rate was comparable to the previous Queensland study $(77.8 \%)^{15}$ when excluding an outlier pharmacy in which the participation rate was compromised by the size of the pharmacy and customer volume. In future studies involving larger pharmacies, it is recommended to coordinate multiple researchers for data collection.

The 15 pharmacies were selected to represent a range of characteristics and locations and with consideration of accessibility for the researchers, rather than statistically, although the key purchasing behaviour data have been remarkably reproducible between surveys. Further research is now recommended on a larger scale, with stratified sampling of pharmacies geographically and by pharmacy type and size to generate nationally representative statistics. This would require cooperation of up to 10 research centres.

\section{Key findings}

The predominance of female customers, $67.2 \%$ of purchasers, is comparable to other applications of this method ${ }^{15,21,24}$, and the predominance of females aged 31-50 years is in agreement with national $^{23}$ and international data. ${ }^{22}$ Female customers were also associated with purchases on behalf of others or for sharing, compared to males, consistent with their role as proxy customers for their children, neighbours and relatives ${ }^{25}$, and suggesting a strong family care role and the need for pharmacies to be positioned for family health care needs.

The incidence of multiple non-prescription medicine purchases, 1.2 different brands or types of non- prescription medicines per transaction, was consistent with the 2004 study $^{15}$, despite the inclusion of four discount pharmacies, which were associated with more multiple purchases, in the current sample. Purchases of two or more packs of the same medicine in the same transaction were also of interest, and occurred notably for analgesics. This behaviour, explored for the first time here, is worthy of further insight in terms of intended use and staff involvement in the sale. Advertised specials at the time of the survey were not able to be accurately recorded.

Most winter medicine sales are expected for coughs, colds, pain and/or nutritional supplementation. The 2004 survey was dominated by respiratory medicines (35.1\% of eligible sales), comparable to the $33.1 \%$ in the current data, excluding an outlier pharmacy in which analgesics sales were over-represented and self-selected (unscheduled) medicines were under-represented due to the positioning of the researcher. Repeated seasonal surveys are warranted to monitor sales trends.

Approximately two-thirds (69.2\%) of the sales were repeat purchases, slightly higher than the 2004 study $(64.7 \%)^{15}$ but possibly biased by the inclusion of discount pharmacies in this sample, where customers may be attracted by lower prices for familiar products. It should not be assumed that repeat purchases are optimal choices; staff should ascertain the intended user, intended use, and previous experiences with that medicine, and offer recommendations as required.

The influence of pharmacy staff in guiding nonprescription medicine choice is supported by a body of literature. ${ }^{12,22,26-28} \quad$ Pharmacy staff were particularly influential in guiding product choice in- 
store in response to symptoms or queries when customers had entered the pharmacy without a particular brand in mind. Recommendations by medical practitioners also guided first-time medicine purchases in both studies. Medical practitioners were also recognised as a significant and increasingly influential source of non-prescription recommendations in a survey of the Irish public. ${ }^{22}$ It is notable that combined sources of advertising were a relatively minor influence on first-time purchases, although it is acknowledged that advertising may prompt brand recognition during repeat purchases. This study proposes that educational advertising directed to pharmacy staff may be more effective in establishing consumers' product preferences than direct-to-consumer advertising.

Consistent with previous research ${ }^{15,24}$ and international reports ${ }^{21,29}$, the majority of nonprescription sales resulted from direct requests from customers who entered the pharmacy with an intention to purchase a particular product. This behaviour was significantly correlated with previous purchase of that medicine. Screening questions by the sales staff to check the intended use and experiences with the product are still advisable at the time of purchase.

Self-selection in no-intended-brand situations is potentially unsafe, occurring in $12.6 \%$ of sales in this study, slightly exceeding the incidence of selfselection in intended-brand purchases (11.0\%). Although medicines legally available for selfselection in Australia are unscheduled and hence of limited potency, drug interactions and use in contraindicated conditions are well documented, as widely recognised with nutritional supplements. ${ }^{30}$ The findings regarding consultation observed during the transaction will be reported elsewhere, in relation to the legal requirements for consultation surrounding the schedule of the medicine and its location in the pharmacy. However, analysis presented here implies a clear role for pharmacy staff in ascertaining the appropriate choice of medicines and advising on their safe and effective use. New data regarding customers' privacy concerns suggest that this role was performed sensitively.

\section{CONCLUSIONS}

This study has provided an updated insight into purchasing behaviour for 3470 medicines from a sample of 15 pharmacies in South-East Queensland, Australia, during one week in midwinter, confirming general descriptors reported previously and introducing new variables and analyses, a selection of which were reported here. The study identified a majority of intended-brand purchases, repeat purchases and purchases for self-use. Despite these being clinically routine, there is a role for pharmacy staff to ensure appropriate choice and use of the medicine. A divergent behaviour was evident in customers without an intended brand, likely to be making an initial purchase, and reliant on in-store recommendations by the pharmacy staff, highlighting the opportunities for pharmacy staff involvement in patient care. Multivariate analysis of the current data and nationwide survey coverage are recommended.

\section{ACKNOWLEDGEMENTS}

The author acknowledges financial support from The University of Queensland FirstLink scheme, and the staff and customers of the 15 pharmacies during the data collection. The following were students who assisted in data collection: Vibashini Appaduri, Amanda Chan, Katie Chi, Ivy Chien, Millie Hsu, Diane Kim, Jerry Lee, Szu-Pei Lin, Khen Ly, Jason Meiers, Suzy Nisbet-Smith, Amber Peckston, Jenny Tian, Kate Waymouth and Rachael Weston.

\section{CONFLICT OF INTEREST}

None declared.

\section{References}

1. Greenwood S. Value of the current system of community pharmacy. Australian Health Consumer 2005-6(1):10, 1, 6.

2. Australian Bureau of Statistics. 2004-5 national health survey: summary of results. Canberra; 2004-5. URL: http://www.ausstats.abs.gov.au/ausstats/subscriber.nsf/0/3B1917236618A042CA25711F00185526/\$File/43640 200405.pdf. (Accessed 16 July, 2008).

3. Australian Institute of Health and Welfare. Australia's health 2006. URL: http://www.aihw.gov.au/publications/index.cfm/title/10321. (Accessed 16 July, 2008).

4. Standard for the uniform scheduling of drugs and poisons. Canberra, Australia: Commonwealth of Australia; 2007.

5. Benrimoj SI, Emmerton L, Taylor R, Williams K, Gilbert A, Quintrell N. Cost benefit analysis of Pharmacist Only and Pharmacy Medicines and a risk based evaluation of the standards; 2005. URL: http://beta.guild.org.au/uploadedfiles/Research_and_Development_Grants_Program/Projects/2001-502_fr.pdf. (Accessed 16 July, 2008).

6. Price Waterhouse Coopers. Scoping study of the Queensland pharmaceutical industry. 2003. URL: http://www.sdi.qld.gov.au/dsdweb/v3/documents/objdirctrled/nonsecure/pdf/9343.pdf\#search=\%22\%22Generic\%20medi cines $\% 22 \% 20$ Australia\%20\%22New\%20Zealand\%22\%20\%22non-prescription\%22\%22. (Accessed 16 July, 2008).

7. Pharmaceutical Society of Australia. Position statement - listing and scheduling of medicines; 2005. URL: http://www.psa.org.au/site.php?id=840. (Accessed 16 July, 2008).

8. Harris C. Pharmacists help combat pseudoephedrine diversion. Austr Pharm. 2005;25(4):266.

9. Roberts S. Project STOP nabs first culprits. Pharmacy News 2006;(Feb 16):2. 
10. National Drugs and Poisons Schedule Committee. Outcome of considerations by the National Drugs and Poisons Schedule Committee at its October 2006 meeting of proposals for amendment to the Standard for the Uniform Scheduling of Drugs and Poisons; 2006. URL: http://www.tga.gov.au/NDPSC/gazette/g0510pos.pdf. (Accessed 16 July, 2008).

11. Krska J, Kennedy E. Expectations and experience of customers purchasing OTC medicines in pharmacies of the North of Scotland. Pharm J. 1996;(256):354-356.

12. Fahey M. Guide to consumers' pharmaceutical purchasing behaviour. J Manag Care Pharm. 1996;2(5):489-499.

13. John D, Evans S. Residents' views and experiences of pharmacy questioning and advice relating to non-prescription medicine purchases. Int J Pharm Pract. 1997;5(2):85-90.

14. Beckerleg S, Lewando-Hundt G, Eddama M, Alem A, Shawa R, Abed Y. Purchasing a quick fix from private pharmacies in the Gaza Strip. Soc Sci Med. 1999;49(11):1489-1500.

15. Emmerton L. Non-prescription medicine purchasing behaviour. Brisbane: The University of Queensland; 2004.

16. Emmerton L. Exploration of two risk scenarios in non-prescription medicine purchases. Int J Pharm Pract. 2006;14(3):219-225.

17. Emmerton L. Development and review of a team project for undergraduate pharmacy students. Pharm Educ. 2006;6(1):71-76.

18. Emmerton L, Shaw J. Non-prescription medicine purchases in New Zealand. J Pharm Mark Manag. 2002;15(1):97-111.

19. Emmerton L, Shaw J. The influence of pharmacy staff in non-prescription medicine sales. Int J Pharm Pract. 2002;10:101-106.

20. Emmerton L. Purchasing behaviour for non-prescription medicines. Aust Pharm. 2005;24(4):326-.30.

21. Shaw J. Consumers' non-prescription medicines purchasing behaviour in community pharmacy. Auckland, NZ: The University of Auckland; 2005.

22. Wazaify M, Shields E, Hughes C, McElnay J. Societal perspectives on over-the-counter (OTC) medicines. Fam Pract. 2005;22(2):170-176.

23. AC Nielsen. ScanTrack Pharmacy; 2006. URL: http://au.acnielsen.com/products/rms_scan_track_pharmacy.shtml. (Accessed 16 July, 2008).

24. Emmerton L, Shaw J. MediTrends: Current market purchasing trends for non-prescription medicines. Dunedin, New Zealand: University of Otago; 2000.

25. Hassell K, Noyce P, Rogers A, Harris J, Wilkinson J. A pathway to the GP: the pharmaceutical 'consultation' as a first port of call in primary health care. Fam Pract. 1997;14(6):498-502.

26. Self-medication: a study undertaken in Wellington, New Zealand. Wellington, NZ: Pharmaceutical Society of New Zealand and New Zealand Pharmacy Education and Research Foundation; 1998.

27. Fisher C, Corrigan O, Henman M. A study of community pharmacy practice. 3. Non-prescribed medicines sales and counselling. J Soc Admin Pharm. 1991;8(2):69-75.

28. Synder R. Consumers' needs and need of registered pharmacist's advice on OTC's. Drug Topics 1997;(141 Nov):71-73.

29. Bond C. POM to P - implications for practice pharmacists. Primary Care Pharmacy 2001;2(Mar):5-7.

30. Newall C, Anderson L, Phillipson J. Herbal medicines: a guide for health-care professionals. London: The Pharmaceutical Press; 1996. 